\title{
ETIOLOGIA DOS ANEURISMAS HELMINTICOS E STRONGILOSE EQUINA (*)
}

\author{
POR \\ Cesar Pinto e Cavalcanti Proença
}

Com 12 figuras no texto e 18 estampas

A Helmintologia está tomando em medicina humana e veterinaria, principalmente nesta, uma importancia tal que somente se póde comparar com o surto que a Bacteriologia teve depois das memoráveis pesquizas de PASTEUR, na França e KocH, na Alemanha.

Com o extraordinário desenvolvimento que a Helmintologia tem tido, nestes 20 anos tornou-se uma ciência autónoma e de importância crecente, porque interessa, sobretudo, os domínios da economia humana e animal. São bem conhecidos os males profundos e devastadores que os helmintos ocasionam para os povos que habitam as zonas de clima quente e húmido. O mesmo ocorre, em escala muitíssimo maior, para toda a criação que o homem faz: bovina, ovina, suina, equina, etc. Nestas criações que são o fundamento da nossa riqueza pecuária, não é possivel dar um grande desenvolvimento sem que se aparelhem os criadores com uma orientação que possa nortea-los no modo de defender e prevenir males muitos dos quais evitáveis.

Não é somente a pecuária que depende, em grande parte, dos conhecimentos relativos á Helmintologia, mas tambem a própria agricultura, que necessita ter amparo cientifico para as doenças ocasionadas por helmintos que acarretam grande destruição nas plantações, impedindo, por vezes, qualquer fórma de cultura, como, aliás, no Brasil sucedeu com grande epifítia ocasionada por helmintos que devastaram as plantações de café no Estado do Rio.

Tomando em alta consideração estes problemas cientificos e, com a larga visão que o caracterisava, foi que Oswaldo Cruz, ao fundar o Instituto de Manguinhos, criou uma secção de Helmintologia.

De acôrdo com as pesquizas realizadas pelos Prof. LaURo TrAvassos, C. Pinto \& Lins de Almeida, no Instituto Oswaldo Cruz, abrangendo cerca de seis mil necrópsias, sabe-se que os helmintos patogénicos para os animais domésticos do Brasil, atingem cerca de 156 espécies, com a seguinte distribuição:

Bovinos, cêrca de 27 espécies.

Ovinos, cêrca de 20 espécies.

(*) Conferência realisada em 31 de Junho de 1936, no Instituto Oswaldo Cruz, em homenagem aos Estudantes argentinos de Medicina Veterinaria, em visita ao Brasil, chefiados pelos Profs. Cánepa e Inchausti, da Fac. de Agr. e Veterinaria, da Universidade de Buenos Áires. 
Caprinos, cêrca de 16 espécies.

Suinos, cêrca de 17 espécies.

Equideos, cêrca de 34 espécies.

Canideos, cêrca de 16 espécies.

Felideos, cêrca de 17 espécies.

Coelhos, cêrca de 4 especies.

Aves, cêrca de 40 espécies.

Os helmintos dos animais domésticos do Brasil, referidos anteriormente são grupados em:

\begin{tabular}{|c|c|c|c|c|c|c|c|c|}
\hline Nematóides. & - & & & & . & & 1 & espécies \\
\hline Cestóides & & & & &  & & 2 & $»$ \\
\hline Trematóides. & . &  &  & . & . & & 2 & $\gg$ \\
\hline Acantocéfalos & & & & . & . & 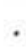 & & 》 \\
\hline
\end{tabular}

E' importante salientar o papel patogénico que certas espécies de helmintos representam mutuamente para o homem e animais, ocasionando doenças de extrema gravidade, como por exemplo, a equinococose ou cisto hidático que, pela vasta distribuição geográfica e elevada incidência nos cães e outros animais receptíveis, é considerada doença de notificação obrigatória, como acontece na Rep. Oriental do Uruguay que a respeito legislou em 1934, creando ainda um Centro de Estudos e Profilaxia da Equinococose, com uma revista especial para as suas publicações, denominada Archivos Internacionales de la Hidatidosis.

A triquinelose (Trichinella spiralis) observada pela primeira vez na Argentina em 1898 pelos Drs. Pedro Berri \& Martin Spuch, com $2,4 \%$ de infestação nos suinos, baixou para 0,1\% em 1934, graças a um serviço modelar de profilaxia desta gravíssima helmintose de alto interesse para a Saúde pública, como tambem para a Pecuária do grande País irmão.

Os fatos citados aqui demonstram exuberantemente que as helmintoses desempenham um papel de extraordinaria importância económica e higiénica e que a luta antihelmíntica deve ser considerada como um problema de interesse internacional.

O estudo da estrongilose dos equídeos tem grande importância em patologia veterinária, sendo imprescindivel conhecer-se a predominância das espécies do gênero Strongylus, porque, diante desses conhecimentos podemos fornecer elementos preciosos para o diagnóstico e para a etiologia dos aneurismas heimínticos, dos chamados nódulos intestinais e tambem para a estrongilose enzoótica dos equídeos.

Sendo as espécies do gênero Strongylus responsáveis por manifestações mórbidas diferentes, impõe-se um estudo rigoroso da inci- 
dência de cada uma delas, pois, conforme demonstraram vários autores, em diversos países, elas ocorrem em porcentagens diferentes.

O diagnóstico de estrongilose é feito pelo exame dos helmintos encontrados nas fezes ou pela necrópsia. V. CILLI (1930) demonstrou que os equídeos atacados de estrongilose apresentam um estado



Fig. 1 - Face lateral da extremidade anterior do macho de Strongylus (Alfortia) edentatus (Looss, 1900). Original. Fig. 2 - Face lateral da extremidade anterior do macho de Strongylus (Strongylus) equinus Mueller, 1780. Original. Cl. Bu. - colar bucal, C. B. cápsula bucal, C. G. E. - conduto da glândula esofageana dorsal, E. - esôfago, C. F. corónula franjanda, P. C. - papila cefálica, D. - os tres dentes do fundo da cápsula bucal, An. - anel nervoso. 
de hipersensibilidade que póde ser evidenciado por injeção de antigeno específico (strongilina). A reação intra palpebral é a que melhor convem, embora a reação subcutânea tambem dê resultado positivo; a reação oftálmica não é positiva.

Agradecemos ao Dr. C. B. Magarinos Torres o valioso auxílio que nos prestou no estudo das lesões aqui referidas.

Os Nematóides deste importante grupo têm as características seguintes:

Superfamília Strongyloidea WeINLAND, 1858.

Nematóides tendo ou não cápsula bucal; esôfago sem bulbo. (Fig. 2). Machos providos de bolsa copuladora tendo seis pares de raios (Figs. 4-7) laterais e um raio impar dorsal (raramente duplo), excetua-se o gênero Muellerius que não possue bolsa copuladora nem raios bursais. Dois espículos. Fêmeas com ovário simples ou duplo. Evolução sem hospedador intermediário.

Família Strongylidae BAIRD, 1853.

Cápsula bucal presente, boca guarnecida por corónula franjeada (Fig. 2). Bolsa copuladora típica. (Fig. 4), Gubernaculo geralmente presente. (Fig. 4) Parasitos do tubo digesttivo.

\section{Subfamília Strongylinae RAILliet, 1893.}

Cápsula bucal relativamente grande, subesférica. (Figs. 1, 2, 3) Vulva geralmente no terço posterior do corpo. (Fig. 10).

\section{Gênero Strongylus Goeze, 1782. \\ Sclerostoma RUdOLPHI, 1809. \\ Sclerostomum Diesing, 1851.}

Strongylinae. Boca com corónula franjeada que tem origem no colar bucal (Fig. 1). Cápsula bucal subglobular, sem corónula franjeada interna, tendo ou não dentes no fundo da cápsula bucal. (Figs. 1, 2, 3) Raio dorsal externo nascendo em tronco comum com o raio dorsal (Fig. 5). Raio dorsal com tres digitações. (Figs. 5, 6, 7) Os adultos são parasitos do grosso intestino dos equídeos.

A. Railliet (1923) dividiu o gênero Strongylus em tres subgêneros, com as características seguintes:

\section{I. subgênero Strongylus Goeze, 1782.}

No fundo da cápsula bucal existem quatro dentes. Espécie tipo: Strongylus (S.) equinus. Fig. 2.

II. subgênero Alfortia RaIlliet, 1923.

No fundo da cápsula bucal não existem dentes. Espécie tipo: Strongylus (Alfortia) edentatus. Fig. 1.

III. subgênero Delafondia RaILliet, 1923.

No fundo da cápsula bucal existem dois dentes. Espécie tipo: Strongylus (Delafondia) vulgaris. Fig. 3. O Strongylus asini tambem pertence á este subgênero. 
Caraterísticas principais das espécies do gênero Strongylus parasitos dos Equídeos

\begin{tabular}{|c|c|c|c|c|c|c|c|}
\hline Espécies & $\begin{array}{l}\text { Compri- } \\
\text { mento do } \\
\text { macho }\end{array}$ & $\begin{array}{l}\text { Compri- } \\
\text { mento da } \\
\text { fêmea }\end{array}$ & $\begin{array}{l}\text { Dentes do fundo } \\
\text { da cápsula bucal }\end{array}$ & $\begin{array}{l}\text { Comprimento } \\
\text { do esôfago do } \\
\text { macho }\end{array}$ & $\begin{array}{l}\text { Comprimento } \\
\text { do esôfago da } \\
\text { têmea }\end{array}$ & $\begin{array}{l}\text { Comprimento } \\
\text { dos espículos }\end{array}$ & Observaçбes \\
\hline $\begin{array}{l}\text { S. equinus MUELLER, } \\
\text { 1780. Figs. } 1,4 .\end{array}$ & $22-35 \mathrm{~mm}$ & $28-55 \mathrm{~mm}$. & $\begin{array}{l}\text { Um subdorsal, grande, } \\
\text { conifórme, com ponta } \\
\text { bífida e dois subven- } \\
\text { trais, pequenos e cónicos }\end{array}$ & $\begin{array}{c}1,7 \text { a } 1,8 \\
\mathrm{~mm} .\end{array}$ & $\begin{array}{c}2,3 \text { a } 2,5 \\
\text { mm. }\end{array}$ & $\begin{array}{c}2,6 \text { a } 2,7 \mathrm{~mm} . \\
\text { raramente } 3,1 \\
\text { mm. }\end{array}$ & $\begin{array}{l}\text { Pouco frequente no } \\
\text { Brasil }(9,88 \%) .\end{array}$ \\
\hline $\begin{array}{l}\text { S. edentatus (Looss, } \\
\text { 1900). Figs. 2, } 4 .\end{array}$ & $20-28 \mathrm{~mm}$ & $28.44 \mathrm{~mm}$. & Ausentes & $1,8 \mathrm{~mm}$. & $2 \mathrm{~mm}$. & $\begin{array}{c}1,9 \text { a } 2,2 \\
\text { mm. }\end{array}$ & $\begin{array}{c}\text { Comum no Brasil } \\
(48,35 \%) .\end{array}$ \\
\hline $\begin{array}{l}\text { S. vulgaris (Looss, } \\
\text { 1900). Figs. } 3,4 \text {. }\end{array}$ & $11-17 \mathrm{~mm}$. & $13-25 \mathrm{~mm}$. & $\begin{array}{l}\text { - Dois, grandes, de ápi- } \\
\text { ces arredondados }\end{array}$ & $\begin{array}{c}1,3 \text { a } 1,4 \\
\mathrm{~mm} .\end{array}$ & $\begin{array}{c}1,5 \text { a } 1,7 \\
\mathrm{~mm} .\end{array}$ & $\begin{array}{c}1,4 \text { a } 2,24 \\
\text { mm. }\end{array}$ & $\begin{array}{c}\text { Comum no Brasil } \\
(41,76 \%) .\end{array}$ \\
\hline $\begin{array}{l}\text { S. asini BOULENGER, } \\
1920 .\end{array}$ & $18-32 \mathrm{~mm}$. & $30-42 \mathrm{~mm}$. & $\begin{array}{l}\text { Dois, grandes, de bor- } \\
\text { do irregulares. }\end{array}$ & $1,6 \mathrm{~mm}$ & $2,4 \mathrm{~mm}$ & $1,6 \mathrm{~mm}$ & $\begin{array}{l}\text { Rara. Ainda não ob- } \\
\text { servada no Brasil. }\end{array}$ \\
\hline
\end{tabular}


Strongylus (Delafondia) vulgaris (Looss, 1900)

Figs. 3, 7-10, 12-22

Strongylus armatus dos autores.

Sclerostoma vulgare Looss, 1900.

Slerostomum bidentatum STICKER, 1901.

Strongylus valgaris RaIL. et. HenRY, 1909.

Strongylus (Delafondia) vulgaris RAIL., 1923.


Fig. 3 - Face lateral da extremidade anterior do macho de Strongylus (Delafondia) vulgaris (Looss, 1900). Fig. 9 - Extremidade anterior da larva do último estádio de Strongylus vulgaris proveniente do aneurisma da Est. 12. C. B. - cápsula bucal, D. dentes, An. - anel nervoso, E. - esôfago, P.e - poro excretor.

Das espécies do gênero Strongylus é esta a mais importante em patologia veterinária por ocasionar aneurismas e nódulos helmínti$\cos$ do intestino grosso e delgado. Os exemplares adultos vivem no cecoue no colon dossequídeos. (Est. 13 e 14) As formas imaturas são encontradas 'nas artérias, gánglios mesentericos e em nódulos submucosos localisados no ceco, noc colon e raramente no intestino delgado. 
Na opinião de Adelmann (1908) Railliet e Henry (1923), os ovos são postos em segmentação pouco adiantada. Nas fezes frescas, a eclosão das larvas inicia-se no fim de dois dias e medem 816 micra de comprimento por 21 micra de largura, possuem a cauda
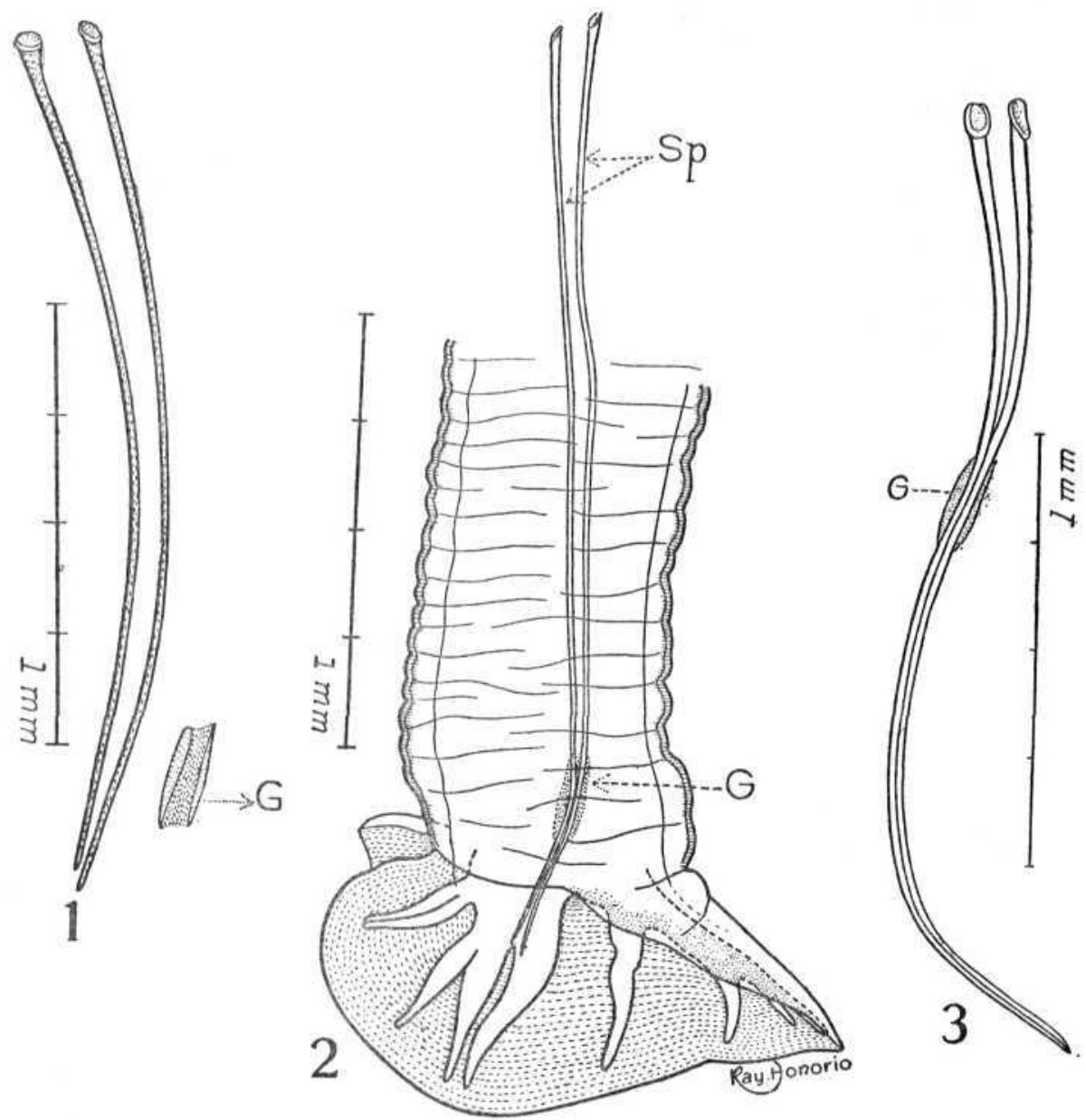

Fig. 4 - A esquerda (1) espículos e gubernáculo (G) de Strongylus (Alfortia) edentatus (Looss, 1900). Original. No centro (2), face lateral da cauda do macho de Strongylus (Delafondia) vulgaris (Looss, 1900); Sp. - espículos. G - gubernáculo. Original. A direita (3), espículos e gubernáculo (G) de Strongylus (Strongylus) equinus Mueller, 1780. Original.

afilada e ligeiramente recurvada. No fim de duas a tres semanas processa-se a primeira muda e o helminto atinge a fase de larva rabditiforme (segundo estádio) tendo já, $1,5 \mathrm{~mm}$. a $2 \mathrm{~mm}$. de comprimento.

De Blieck \& Baudet (1926) cultivaram as larvas de S. vulgaris e $S$. edentatus em placas de Petri contendo água e mantidas á 
temperatura de $30^{\circ} \mathrm{C}$. Ao nascerem dos ovos $\left({ }^{*}\right)$ constituem as larvas do primeiro estádio; após a primeira muda atingem o segundo estádio e depois da segunda muda são larvas do terceiro estádio. No fim de um dia de cultura observam-se ovos com mórulas, ovos contendo larvas vivas e tambem larvas livres. Estas são rabditiformes, têm a dilatação piriforme do esôfago e o intestino possúe a luz muito ondulada. Após cêrca de 42 a 45 horas a larva rabditiforme abandona a antiga cutícula, a cauda é mais ou menos longa e o aspecto rabditiforme do esôfago é mais nítido; o intestino é bem visivel, notando-se os contornos das células intestinais, e a mancha genital aparece no fim de 3 a 8 dias.

Geralmente a segunda muda é feita após 5-8 dias; depois desta mudança de pele, as larvas permanecem sob a antiga cutícula, são muito resistentes e conhecidas pelo nome de larvas encistadas. Em temperatura comum, De BliecK \& BAUdet (1926) conservaram-nas vivas durante 4 mêses sem que perdesssem a mobilidade e observaram que são muito resistentes ao frio. As larvas que fizeram a segunda muda, mantidas nas fezes, não resistem á dessecação.

O quarto estádio larval é observado nas larvas (Figs. 9,10) contidas nos aneurismas das artérias (grande mesentérica etc.) e segundo Railliet e Henry as larvas então medem 2 a 6 milimetros de comprimento. Após esta mudança de pele o helminto atinge a fase adulta, abandonando a localisação intravascular, sendo levado pela circulação sanguínea até as menores ramificações das artérias mesentéricas, penetrando na submucosa do intestino e aí formando os nódulos helmínticos (Est. 22-A) de onde saem para a luz do intestino, afim de completarem a maturidade sexual.

Infestação experimental. - DE BLIECK \& Baudet (1926) verificaram que as larvas encistadas de $S$. vulgaris e S. edentatus são infestantes para os potrilhos, ratos, camondongos e cobáias.

Os autores em geral, admitem que as larvas de Strongylus penetram pela boca dos equínos. Schlegel e Adelmann acreditam que o desenvolvimento seja direto e HENRY admite, sem provas experimentais, o ciclo de Looss, com infestação possivel, via cutânea.

Nos camondongos e cobáios infestados pela boca e sacrificados em diferentes intervalos, DE BLIECK \& BAUDET (1926), encontraram larvas sómente no intestino. Em dois potrilhos isentos de helmintos e criados com o fim especial para estas pesquisas, com um e quatro mêses de idade, estes autores obtiveram a infestação daqueles animais,

(*) A ação da luz é nociva para os ovos de $S$. vulgaris e $S$. edentatus. 
após ingestão de larvas de $S$. vulgaris e $S$. edentatus; no fim de 6 ou 7 semanas verificaram ovos de Strangylus nas fezes dos potrilhos; a necrópsia destes revelou formas evolutivas de $S$. vulgaris no mesentério e de $S$. edentatus sob o peritôneo. Um potrilho infestado por via subcu-


Fig.j - Bolsa copuladora de Strongylus (Alfortia) edentatus (Looss, 1900). Original. v. v. - raio ventro-ventral. v. I. - raio ventro-lateral. 1. a - raio lateral-anterior. 1. m. raio lateral-médio. I. p. - raio lateral-posterior. d. e. - raio dorsal externo. d-raio dorsal Fig. 6 - Bolsa copuladora de Strongylus (Strongylus) equinus Mueller, 1780. Origiral, Fig. 7 - Bolsa copuladora de Strongylus (Delafondia) vulgaris (Looss, 1900). Original.

tanea, com larvas de S. vulgaris e S. edentatus, após 5 mêses, apresentou ovos destes helmintos nas fezes e a necrópsia revelou formas adultas no ceco.

\section{ANEURISMAS HELMÍNTICOS}

Embora o Strongylus vulgaris fosse descoberto por A. Looss en 1900, ja em 1665 Ruysch havia observado grande número de pe- 
quenos vermes num aneurisma da artéria mesentérica do cavalo, o que foi confirmado por J. H. Schulze (1725), Chabert (1782), Rudolphi (1809), Hodgson (1815), Rigot (1827) etc.

Os aneurismas helmínticos são encontrados em diversas artérias, (Est. 12, 16, 17, 18) principalmente em certos ramos vicerais da aorta posterior dos equídeos; cavalo, mula, asno e zebra.

Segundo Hering, é raro encontrar-se um cavalo sem aneurisma helmíntico e na opinião de Bollinger, 90-94\% dos cavalos da Alemanha são portadores desta lesão parasitária.

Tambem são observados com menor frequência nos potrilhos com tres mêses de idade e até no féto, segundo PoEPPEL (1897).

E' comum observar-se mais de um aneurisma num mesmo animal. Em 65 cavalos, HerING verificou as seguintes localisaçōes:

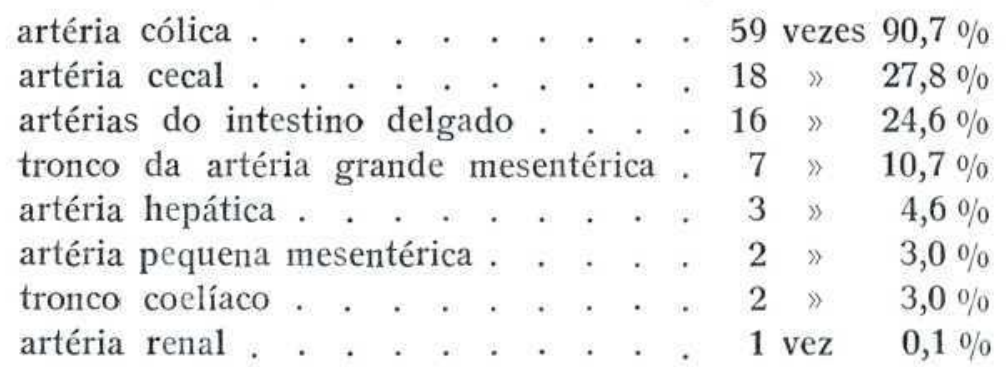

Tambem foram registrados aneurismas helmínticos na artéria testicular e artérias do encéfalo.

Anatomia patológica. - O aneurisma helmíntico é geralmente fusiforme (Est. 17) ás vezes globuloso (Est. 12) ou cilindróide e seu volume médio é de 2 centímetros, podendo atingir ou ultrapassar as dimensões da cabeça de um homem. Segundo Durieux ás vezes não existe dilatação da artéria, apezar das lesões graves de trombose que o vaso póde apressentar.

As larvas de Strongylus vulgaris (Est. 12, Figs. 9, 10) medindo 4 a 5 milímetros de comprimento localisam-se primeiramente nos vasa vasorum dilatando-os e obliterando a túnica média, dando origem a infarctos hemorrágicos e mesarterite aguda, seguida de periarterite, com espessamento da túnica externa e formação de tecido fibroso resistente. (Est. 19, 20, 21, 22).

YoRKE e MACFIE (1919) observaram aneurismas da artéria mesentérica e seus ramos, produzidos por grande número de larvas de $S$. vulgaris medindo 10 a 16 milímetros de comprimento.

Atingindo 8 a 10 milímetros de comprimento, as larvas emigram para a luz da artéria, levantando a túnica interna em ceros pontos. Lesada esta túnica, dá-se a formação de trombos. 
Na ocasião da formação do trombo, o vaso dilata-se, constituindose o aneurisma.

Devido ás reinfestações sucessivas, os aneurismas contêm larvas quasi sempre, sendo, entretanto, rara a ruptura destes aneurismas.

A túnica externa é geralmente espessada e de consistência variavel, segundo a idade do tumor que adere fortemente ás partes visinhas e confunde-se mais ou menos com o tecido conjuntivo próximo.
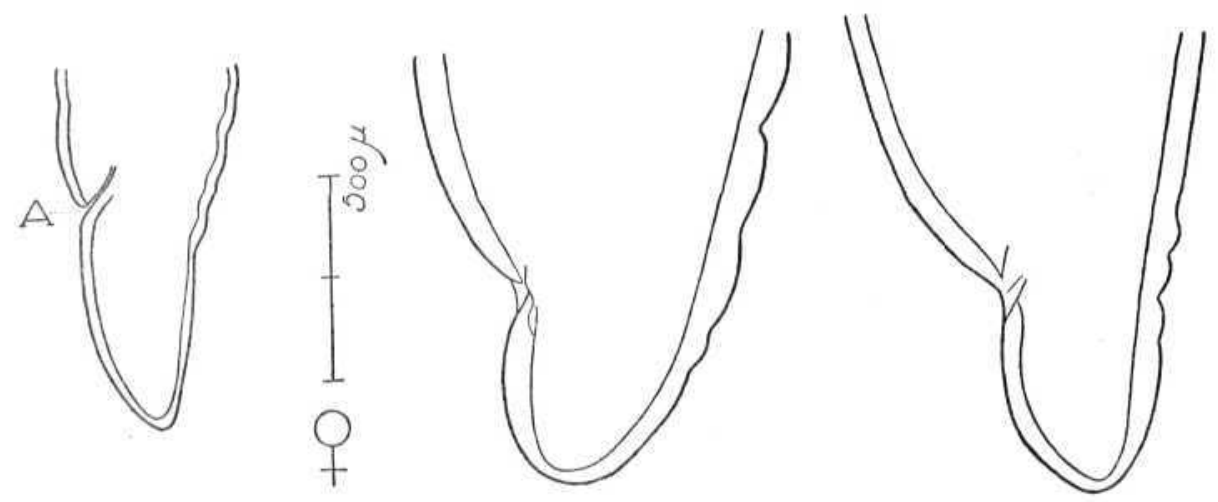

Fig. 8 - A esquerda, cauda de Strongylus vulgaris; ao centro cauda de Strongylus edentatus e á direita, cauda de Strongylus equinus. Original. Todos os desenhos, feitos na mesma escala. A - anus.

A túnica média é sempre hipertrofiada e ás vezes em grandes proporções. Sua espessura, que normalmente é de cerca de um milímetro, pode atingir ou ultrapassar dois centímetros. Este espessamento póde ser uma simples hipertrofia da túnica, ou é devido a fenomenos inflamatórios, com atrofia das fibras musculares.

A túnica interna é quasi sempre alterada, podendo apresentar todos os gráos de endarterite e metamorfose regressiva, desde os espessamentos parciais, coloração esbranquiçada, leitosa, até a ulceração, transformação ateromatosa e calcificação. Esta, sempre rara, pode excepcionalmente adquirir o aspecto de verdadeira ossificação.

No interior do aneurisma existe geralmente um deposito fibrinoso, um trombo, sempre aderente á túnica interna. (Est. 12, 18) Esse trombo é mais ou menos regular, mais ou menos consistente e oblitera em maior ou menor escala a luz do vaso, porém, é sempre atravessado no meio por um canal que dá livre passagem ao sangue. Este trombo prolonga-se geralmente na artéria, para deante e para trás do aneurisma. E' susceptivel de se organizar nas suas camadas mais externas. Sua formação está essencialmente ligada á presença 
dos helmintos, aos processos inflamátorios, ulcerativos e regressivos da túnica interna e á dilatação do vaso.

Os helmintos são encontrados em $90 \%$ dos aneurismas e o número de larvas neles contidas pode variar entre 9 até 400 exemplares. $\mathrm{Na}$ ausência destes parasitos as lesões têm aspecto cronico, e são mais ou menos agudas quando eles se acham presentes.

As larvas de $S$. vulgaris encontradas nos aneurismas são de colorido róseo, medem geralmente, um a tres centímetros de comprimento, apresentam caracteres sexuais esboçados, com os orgãos genitais imaturos. Sofrem aí uma muda e a cápsula bucal já possue caracteres definitivos. (Fig. 9) Algumas dessas larvas se apresentam completamente livres na cavidade da artéria, a maioria, porém, é mais ou menos intrometida nas camadas do trombo, com a cabeça ou a extremidade caudal mais ou menos saliente na corrente sanguínea. São tambem observadas nas paredes hipertrofiadas da artéria, isto é, na túnica interna, na túnica média ou entre estas duas túnicas. As peles ou mudas dessas larvas tambem são encontradas aí.

Conforme acentuou Bollinger, a gravidade dos aneurismas helmínticos não é apenas a ruptura do vaso, o que, aliás é raro, porém, a frequência e a gravidade das cólicas nos equídeos, que aquele autor em 1870, individualisou sob o nome de simdrome cólico-trombo e mbólico.

Patologia. - Os coágulos formados no interior da artéria grande mesentérica ou nas outras artérias sujeitas aos aneurismas helmínticos, podem deixar escapar um ou mais fragmentos, que levados pelo sangue, constituem embolias nas ramificações arteriais destinadas ao tubo intestinal. De acôrdo com o volume do embolo, a artéria obliterada sofre subitamente uma anemia ou isquemia da porção do inttestino á qual se distribue, havendo paralisia de uma ou várias alças intestinais, cujas secreções e movimentos são suspensos. A porção isquemiada do intestino torna-se pálida e depois vermelha escura; ha um intumecimento da mucosa, infarctos hemorrágicos, exsudatos serosos, equimoses e ás vezes aumento consideravel de volume do orgão.

As perturbações circulatorias do intestino determinam sua paralisia local e fermentação do seu conteudo, com produção abundante de gazes.

A parte esquerda do grosso colon, isto é, a porção livre deste orgão, é a mais sujeita a embolias e tromboses.

A paralisia do intestino acarreta comumente a ruptura deste orgão, do estômago ou do diafragma, devido ás fermentações e acúmulo enorme de fezes e gazes. 


\section{NÓDULOS INTESTINAIS}

Os nódulos intestinais produzidos pelo Strongylus vulgaris são sempre submucosos, isolados ou reunidos em pequenos grupos, localisados em diversos pontos do intestino grosso, ás vezes no intestina delgado; sua séde predileta, porém, é a região superior esquerda do grosso colon. Suas dimensões atingem ou ultrapassam as de um grão de ervilha e são contornados por uma zona inflamatória.
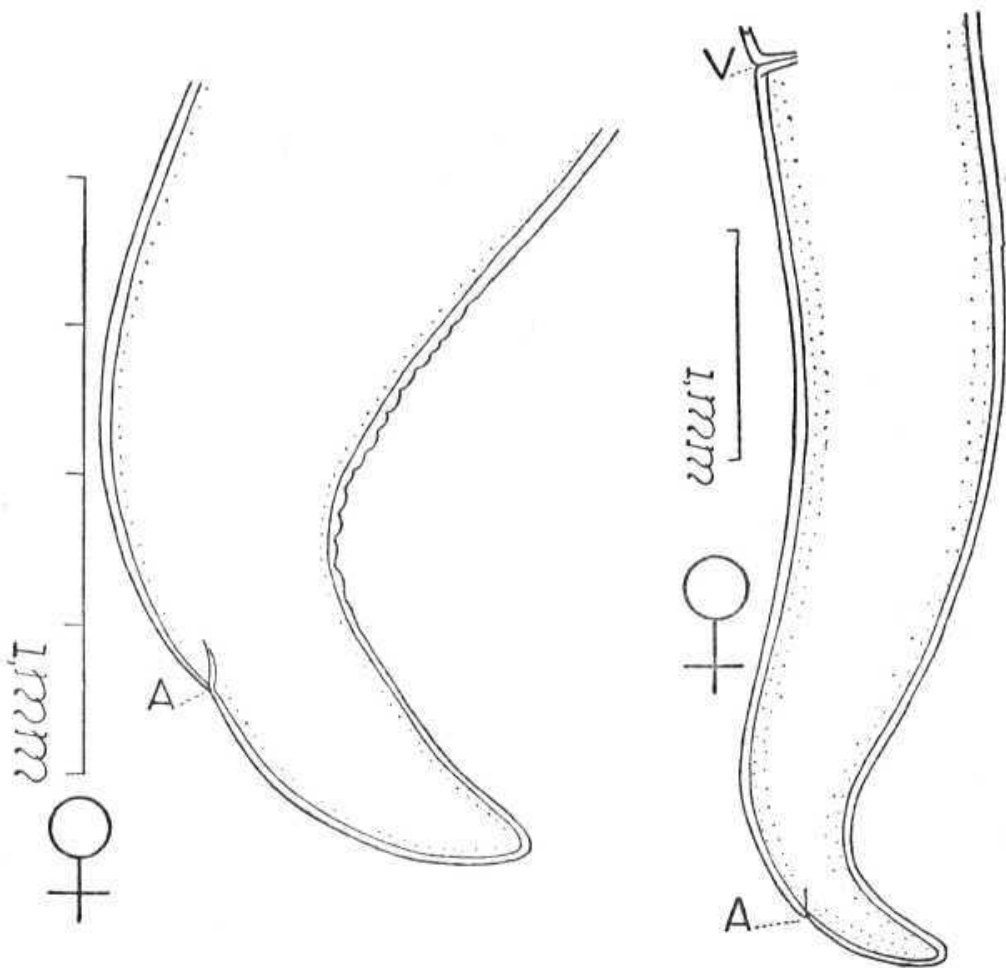

Fig. 10 - Perfil da cauda da larva do ultimo estadio de Strongylus vulgaris proveniente do aneurisma da Est. 12. A - anus. V vulva. Segundo C. Pinto \& C. Proença. 1936. O Campo. 7 (79): 53.

Os nódulos são formados por uma membrana conjuntiva de espessura variavel e por uma cavidade simples ou sinuosa, encerrando um helminto enrolado sobre si mesmo, medindo 16 a 20 milímetros, contido numa substancia de colorido escuro. Os nódulos vasios apresentam um orifício crateriforme com um milímetro de largura por onde o helminto sáe para a luz do intestino. Os nódulos do estomago são produzidos por Draschia megastoma. (Est. 23, 24, 25).

Nas imediações dos nódulos intestinais a muscularis mucosae desaparece quasi por completo e na submucosa observam-se leucocitos polinucleares e mononucleares. 
O abcesso do intestino contendo o Strongylus vulgaris, na última fase larval, mede cêrca de 1,5 centímetro de comprimento por cêrca de 5 milímetros de largura (Est. 22-A), é limitado por uma cápsula conjuntiva, assaz espessa. A mucosa e a submucosa são fortemente recalcadas para a cavidade do intestino, sendo a mucosa bem conservada. Das túnicas do intestino a mais comprometida é a muscular a qual desaparece completamente na porção média da lesão. Nos dois extremos da lesão, o tecido conjuntivo proliferado, penetra até certa extensão, nessa túnica muscular. São dignas de nota as lesões de endarterite obliterante nos vasos da submucosa.

YoRKE e MACFIE (1919) observaram cistos no duodeno e no colon produzidos por larvas e formas adultas de $S$. vulgaris e $S$. edentatus.

\section{NÓDULOS PULMONARES, HEPATICOS E RENAIS}

As larvas de Strongylus vulgaris associadas ás de Habronema ocasionam nódulos pulmonares tambem conhecidos por nódulos translúcidos que são resistentes, arredondados, atingindo o tamanho de um grão de milho ou de lentilha, localisados no parênquima pulmonar, principalmente sob a pleura, dando, pela apalpação, a impressão de grãos de chumbo. Estes nódulos são pardacentos, semi-transparentes, encerram uma larva de nematoide e pela regressão tornam-se calcificados, desaparecendo quasi que por completo a larva neles contida.

Os nódulos helmínticos têm grande semelhança com os nódulos mormosos dos quais se distinguem, principalmente, pela presença de células eosinófilas que faltam nos nódulos produzidos pelo mormo.

No fígado e nos rins encontram-se nódulos semelhantes aos produzidos pelo $S$. vulgaris.

O S, vulgaris é cosmopolita e parasita o cavalo, a mula, o asno e a zebra. No Brasil esta espécie é comum; encontramo-la em $41,76 \%$ dos equídeos que necropsiamos.

Strongylus (Alfortia) edentatus (Looss, 1900)

Figs. 1, 4, 5, 8, 11. Est. 13, 14, 15, 26, 27

Sclerostoma edentatum Looss, 1900.

Strongylus edentatus RaIL. et HENRY, 1909.

Strongylus (Alfortia) edentatus RailLiet, 1923.

Esta espécie póde ocasionar enzootias graves, principalmente nos poldros, localisando-se os helmíntos adultos no ceco e colon dos cavalos e asnos, de preferência na união destas duas regiões do grosso intestino, inclusive até o recto. (Est. 13, 14). 

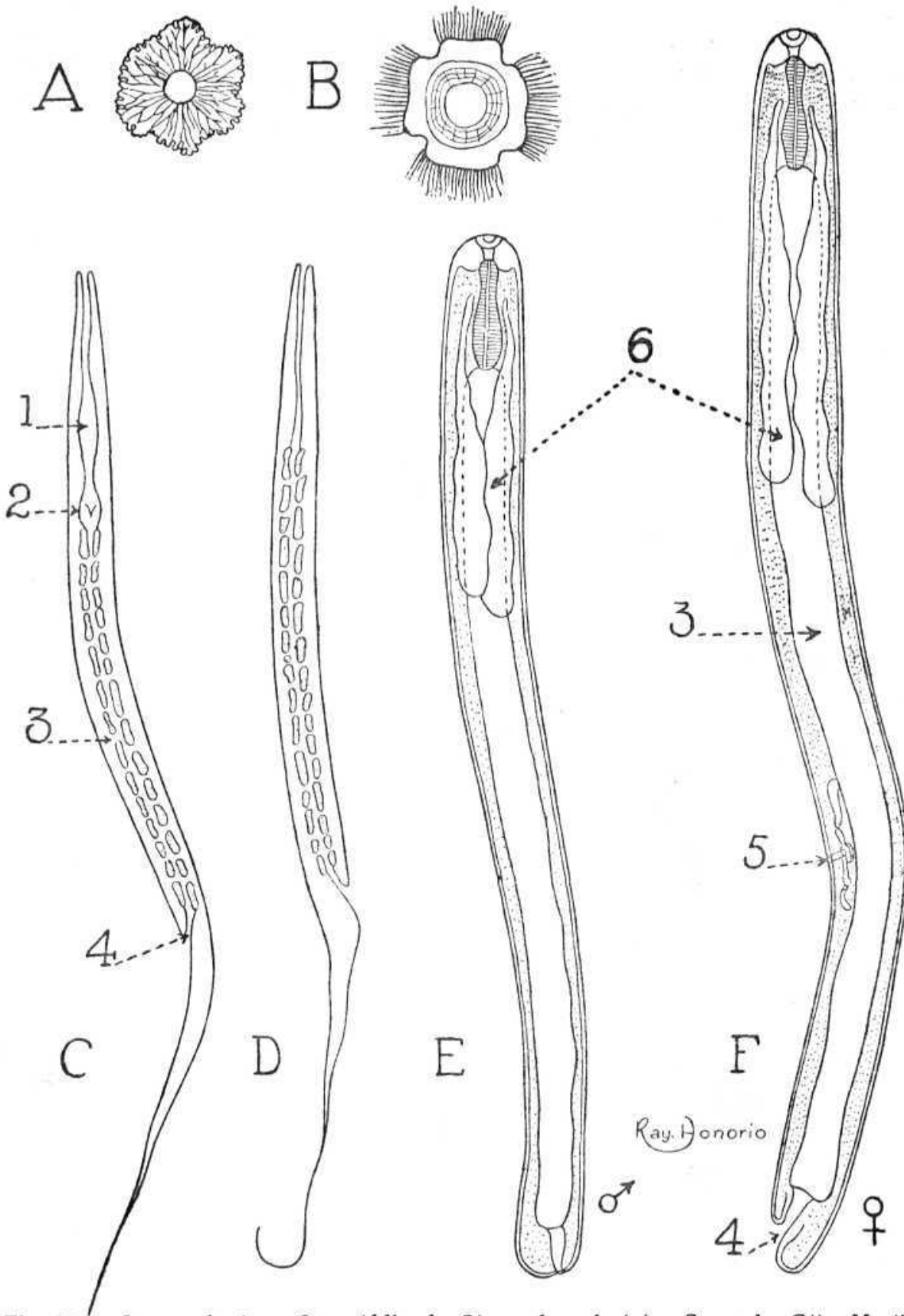

Fig. 11 - Larvas do 1.0 e 2.0 estádio de Strongylus edentatus. Segundo Otto Martin. 1911. Arch. f. wiss. 8 prakt. Tierheilk. $37(1,2): 106-151$. T. 1.; figs. 1-6. A. B. - rosetas da cápsula bucal, vistas anteriormente. C - larva rhabditiforme. D - embrião. E - larva do 20 estádio (macho). F - larva do 2.0 estádio (femea). 1 - esôfago. 2 - bulbo esofagiano. 3-intestino. 4 - anus. 5 - aparelho genital. 6 - glândulas cervicais. 
As primeiras fases evolutivas do S. edentatus foram estudadas principalmente por O. MARTIN (1910) na Alemanha. Os ovos medem 69-87 micra de comprimento por 40-57 micra de largura e são expelidos com as fezes. Na água observa-se a segmentação dos ovos, com numerosas eclosões, desde o terceiro dia.

As larvas do primeiro estádio (Fig. 11) medem 310-410 micra por 12-15 micra de largura, possuem um esôfago cilíndrico e um longo apêndice caudal; na água pura vivem poucos dias; nas fezes entretanto, atingem aproximadamente 900 micra de comprimento por 24 micra de largura, no fim de 20 a 25 dias; possuem a cabeça arredondada e ligeiramente truncada, o corpo atinge maior largura no terço anterior, terminando por uma cauda fina, medindo cêrca de um terço do comprimento da larva; o esôfago é estreito, sem dilatações. No fim de 20 a 30 dias já se observa o segundo estádio larval sob a pele da larva do primeiro estádio e no fim de 40 a 60 dias processase a muda de segundo estádio.

As larvas do segundo estádio são rabditiformes, com 1,2 a 2,2 milímetros de comprimento por 33 a 60 micra de largura e a cauda é ligeiramente mais curta do que no primeiro estádio.

As formas imaturas dos dois últimos estádios são bem conhecidas e localisam-se de preférência, no tecido conjuntivo subperitoneal da membrana parietal, no hipocondrio, nos flancos, na região lombar e na face inferior dos rins, não sendo raro encontra-las tambem nas imediações do umbigo e do apêndice xifóide. O lado direito do corpo dos equídeos é mais sujeito á invasão das formas imaturas deste helminto do que o lado esquerdo, principalmente na região cecal desprovida de serosa. A. RallLiet (1923) tambem encontrou estas formas em liberdade na cavidade peritoneal, na bainha vaginal, nos testículos dos animais com criptorquídia, nos ligamentos do figado, sob a pleura e até nos músculos da perna.

As larvas do quarto estádio são esbranquiçadas ou avermelhadas, de acôrdo com a quantidade de sangue contido no seu tubo digestivo. Nas fórmas com 4 a 7 milímetros de comprimento é possivel distinguir-se os sexos. O corpo tem maior diámetro no terço anterior de onde atenua-se ligeiramente para diante e um pouco para trás; a cabeça é arredondada, a cauda é mais ou menos romba e a cutícula é lisa. O orifício bucal é contornado por uma placa sob a fórma de roseta constituida por um anel central refringente e por uma zona periférica dividida geralmente em quatro lóbulos, sendo dois medianos e dois laterais, guarnecidos exteriormente por láminas muito finas; os lóbulos laterais são ligeiramente chanfrados no meio, semelhantes à roseta com seis laminas no Strongylus vulgaris. 


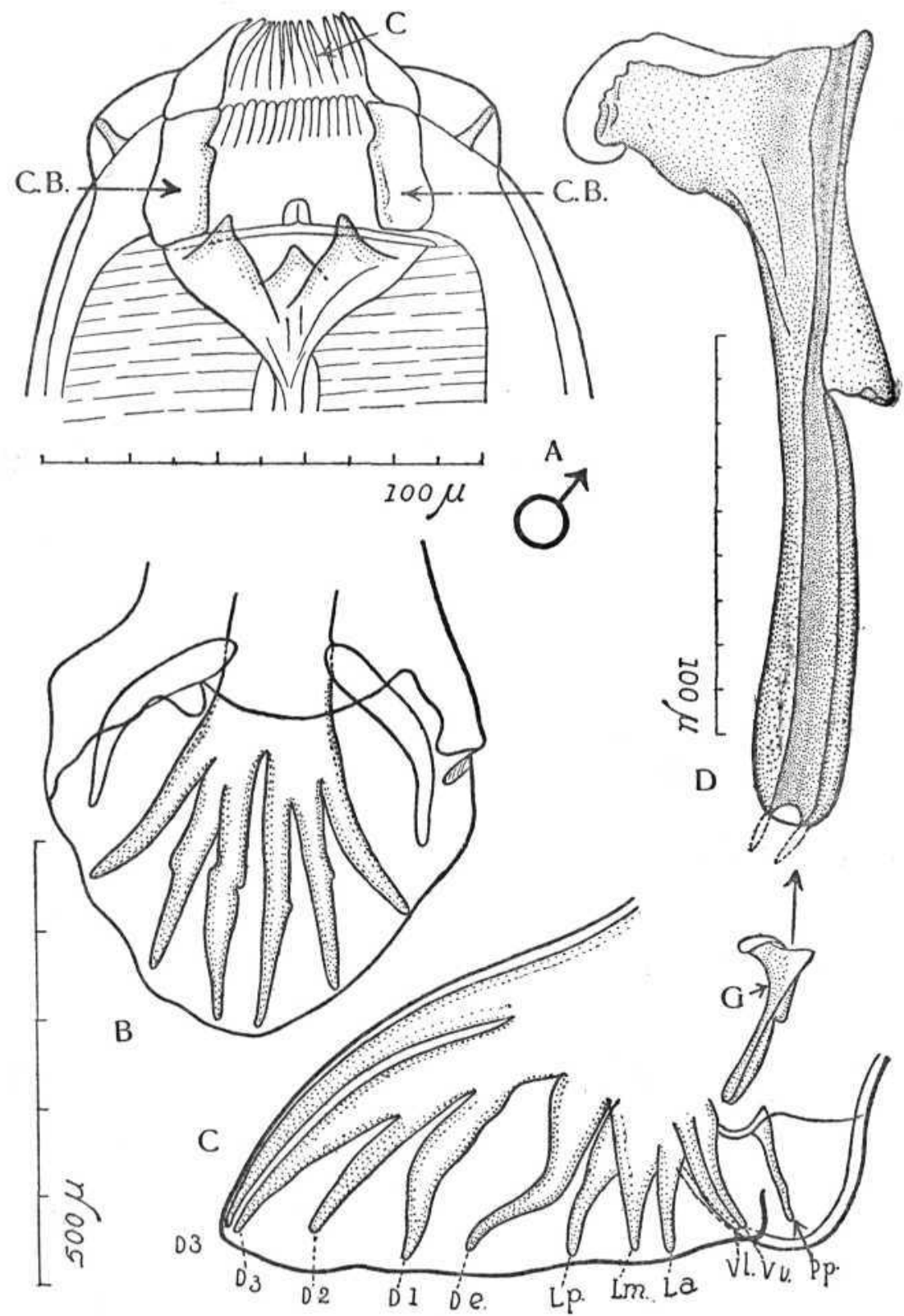

Fig. 29 - Trichonema (Cylicocercus) goldi (Boul., 1917), exemplar da última muda, proveniente de um aneurisma helmíntico, representado na Est. 12. A - face dorsal da extremidade anterior. C. B - capsula bucal. C - coronula franjada externa. B. C. bolsa copuladora, de face e de perfil, vendo-se o gubernaculo, em G. P p. - papila pre-bursal; os raios bursais estão indicados de V. V. até D3. D-gubernaculo, com forte aumento. Segundo C. Pinto \& C. Proença. O Campo. 7 (79): 54; fig. 3. 
As larvas infestantes penetram com os alimentos e a água. Do tubo digestivo atingem a serosa do peritôneo através do sistema vascular. Após a terceira muda penetram entre as duas membranas do peritôneo e finalmente atingem a parede do colon e do ceco onde ocasionam nódulos sob a mucosa.

As larvas atingem a maturidade sexual após abandonarem os nódulos do tubo digestivo.

As espécies do gênero Strongylus fixam-se fortemente na parede do intestino conforme se vê na estampa 26; a porção do tecido contida na boca do helmínto, tem estrutura semelhante á da submucosa; em sua porção basal estreitada e pediculada existe necrose das células aí presentes. O pequeno fragmento das paredes do intestino contido na boca do helmínto não é mais recoberto pela mucosa. $\mathrm{Na}$ submucosa existe apenas infiltração discreta por leucocitos eosinófilos na visinhança dos vasos.

No Brasil o Strongylus edentatus é comum, pois, encontramo-lo em $48,35 \%$ dos equídeos necropsiados.

Espécie cosmopolita, parasita do cavalo, mula, asno e zebra.

\section{Strongylus (Strongylus) equinus (O. F. Mueller, 1784).}

Figs. 2, 4, 6, 8. Est. 13, 14, 15, 28.

Strongylus armatus RuD., 1802.

Sclerostoma equinum BtaINV., 1828.

Strongylus neglectus POEPPEL, 1897.

Sclerostomum equinum Looss, 1900.

Sclerostomum quadridentatum STICKER, 1901, nec DuJ., 1845.

Esta especie ocasiona uma diarréia sem graves consequências. Os exemplares adultos vivem no grosso intestino, especialmente no ceco dos equídeos (Est. 13, 14). Os adultos localisam-se no ceco, raramente no grosso colon e na opinião de A. RaIlliet, o Strongylus equinus é o helminto dos parenquimas; as larvas são encontradas no fígado (Est. 28), pâncreas, pulmões, testículos, tecido conjuntivo subperitoneal, tecido subpleural, ligamento gastro-hepático e em nódulos submucosos do intestino, principalmene no ceco.

Segundo THWAIT (1928), no asno, as larvas do terceiro estádio penetram com os alimentos e alcançam o colon e o ceco; atingem o pâncreas, os pulmões e o fígado directamente através da paręde do tubo digestivo, sendo encontradas comumente no fígado (Est. 28).

As fórmas imaturas do quarto estádio, são elementos com 10 a 15 milímetros de comprimento e possuem uma placa bucal em roseta. 
Os elementos com 37 milímetros de comprimento já possuem a cápsula bucal definitiva, marcando o estádio adulto; estas fórmas são encontradas no parênquima do pâncreas e raramente no fígado, pulmão e ligamento hepato-gástrico.

Os ovos são postos pelas fêmeas e são expelidos com as fezes, desenvolvendo-se na água ou nas fezes húmidas. A larva rhabditóide nasce no fim de 3 a 8 dias e mede 340 a 500 micra de comprimento, transformando-se em primeira larva strongilóide com 1 a 2 milímetros de comprimento e cáuda afilada; após uma muda e sem abandonar a antiga cutícula, transforma-se em s egunda 1 a rva strongilóide encistada que é infestante quando ingerida com os vegetais ou água potavel; ao chegar no intestino dos equinos a larva abandona a cutícula. Em vez de atingir diretamente o ceco, a larva atravessa a parede do intestino e provavelmente através da via sanguínea atinge os diversos orgãos: fígado, pâncreas, pulmões, testículos etc., encistando-se depois na mucosa do ceco e do colon. Estas larvas encistadas e contidas em nódulos do tamanho de uma ervilha, continuam o seu desenvolvimento, adquirem a cápsula bucal e a bolsa copuladora porém, não têm os orgãos genitais desenvolvidos; desses nódulos as larvas passam para a luz do ceco onde adquirem os caracteres adultos.

A estrongilose por Strongylus equinus é comum principalmente no verão, sendo acompanhada de emagrecimento, diarréia, anemia e ás vezes cólicas. Os animais adultos são mais suscetíveis.

O epitélio do ceco é ás vezes completamente destruido ao nivel da implantação dos helmíntos que são hematófagos.

WeINBERg demonstrou que o $S$. equinus secreta uma hemotoxina que dissolve as hematias do cavalo, termoestavel, mesmo quando aquecida durante quinze a vinte minutos á temperatura de $115-120^{\circ} \mathrm{C}$, essa hemotoxina tambem dissolve as hematias do cobaio, coelho, boi e carneiro. Este helmínto tambem secreta uma substância possuindo as propriedades das precipitinas, em presença do sôro de cavalo e do coelho. Quando as larvas se localisam no pâncreas, ocasionam uma pancreatite, com cistos sero-sanguinolentos. Nos testículos dos equinos ocasionam a destruição do tecido glandular e formação de tecido conjuntivo fibroso.

Espécie parasita do cavalo, mula, asno e zebra. Cosmopolita. No Brasil é pouco frequente; encontramo-la em 9,88\% dos equídeos que necropsiamos no Rio de Janeiro. 


\section{SURTO EPIZOÓTICO DE STRONGILOSE}

Observamos um surto epizoótico de strongilose por Strongylus edentatus, $S$. vulgaris e $S$. equinus num lote de 22 equinos mantidos numa fazenda em Irajá (Distrito Federal), cujos campos são invadidos pelas águas no período das chuvas, transformando-se em banhados.

Os primeiros casos graves de strongilose, acompanhados de anemia, grande emagrecimento (alguns animais perderam cem ou mais quilos de peso) e fraqueza do trem posterior, apareceram cêrca de quarenta dias após os animais serem colocados em tais pastos. Um mês depois dêste período os equinos foram retirados deste fóco epizoótico e submetidos ao tratamento anti-helmíntico pelo sulfureto de carbono. A maioria deles melhorou consideravelmente e nos restantes a helmíntose evolveu para a morte. As Estampas 12, 13, 14, 15, mostram a grande infestação de um dos cavalos (cavalo n. ${ }^{\circ} 240$ ) necropsiado in extremis e a Est. 12 mostra o aneurisma de tipo globuloso, da artéria grande mesentérica, produzidio pelas fórmas imaturas do Strongylus vulgaris e no qual tambem observamos o Trichonema goldi (Boulenger, 1917) registrado pela primeira vez no Brasil (Fig. 29).

\section{FREQUÊNCIA DAS ESPÉCIES DE STRONGYLUS NO BRASIL}

Em 13 cavalos necrópsiados com o fim especial para o estudo da incidência das espécies de Strongylus, provenientes do Distrito Federal e Est. do Rio G. do Sul (Brasil) verificamos os seguintes resultados:

\begin{tabular}{c|c|c|c|c}
\hline $\begin{array}{c}\text { Cavalos } \\
\text { número }\end{array}$ & S. vulgaris & S. edentatus & S. equinus & $\begin{array}{c}\text { Total dos } \\
\text { exemplares de } \\
\text { Strongylus }\end{array}$ \\
\hline \hline & & & & \\
179 & 48 & 83 & 7 & 138 \\
232 & 15 & 9 & 7 & 31 \\
233 & 23 & 72 & 8 & 103 \\
234 & 1 & 14 & 4 & 19 \\
236 & 93 & 41 & 8 & 142 \\
237 & 27 & 28 & 0 & 74 \\
238 & 22 & 100 & 30 & 210 \\
240 & 80 & 20 & 8 & 57 \\
241 & 29 & 7 & 12 & 38 \\
242 & 19 & 26 & 5 & 48 \\
243 & 17 & 26 & 4 & 60 \\
245 & 28 & 49 & 102 & 59 \\
246 & 29 & 26 & $9,88 \%$ & 1.032 \\
\cline { 2 - 4 } Total . . & 431 & 499 & \\
Porcentagens & $41,76 \%$ & $48,35 \%$ & & \\
\hline
\end{tabular}




\section{SUMMARY}

The authors, studying aneurysmae of horses, have found last stage larvae of Strongylus vulgaris and one male specimen of Trichone ma goldi, also in the last moult, collected from coagules of an aneurysma of great mesenteric arteria of horse 240 (Distrito Federal, Brasil). In the intestine of this animal the authors found an adult male of Trich on e m a goldi. (Fig. 29). This Trichonemid, which is indeed a blood sucking nematode, is for the first time recorded in Brasil. The authors observed a focus of strongylose (Strongylus edentatus, S. vulgaris and S. equinus) in Irajá (Distrito Fede$\mathrm{ral})$. All the horses (22 animals) brought in from other parts, on $\mathrm{Fe}$ bruary 1936, became ill after being on the affected area for some time, the first severe cases of strongylosis occurring at the end of March, 1936. These cases were acompanied by anemia, progressive inanition (some horses having lost in weight nearly one hundred kilos or more), weakness of the posterior train, followed by death.

Est. 12, 13, 14, 15, show the great infestation of the horse n. 240 and Est. 12 shows the aneurysma with larvae of Strongylus vulgaris (Figs. 9, 10), and Trichonema goldi. (Fig. 29).

\section{BIBLIOGRAFIA ( $\left.{ }^{1}\right)$}

(*) AdelmanN - 1908 - Das Aneurysma verminosum equi von pathologisch-anatom. statist. klin. u. zool. Standpunkte. Arch. f. wiss. prakt. Tierheilk. 34 (3), 297-342, T. 11 .

Benoit, R. - 1935 - Contrib. á l'étude, des nodules et des Kystes parasitaires du foie chez le cheval. Schweiz. Arch. Tierheilk. Zürich. 77, 462-470.

Bhalerao, G. D. - 1935 - Helminth Parasit. of the Dom Anim. in India. Sci. Monogr. 6. Imp. Counc. of Agric. Res. Delhi. p. 166-170. Figs. 87-89.

Bollinger - 1870 - Die Kolik der Pferde und das Wurmaneurysma der Eingeweidearterien. München.

Bosso, G. - 1895 - Esper. sul ciclo evol. d. strongilo armato del cavallo. Giorn. di med. vet. prat. 44 (7), 277-8.

Boulenger, CH. L. - 1920 - Sclerostomes of the donkeys in Zanzibar and East Africa. Parasitol. 12 (1), 27-32, Figs. 1-2.

Cameron, TH. W. M. $-1934-$ The Internal Paras. of Dom. Anim. A Manual for Vet. Surg. London. 80-86, Figs. 33-35.

Chabert - 1782 - Traité d. malad. vermineuses dans les animaux. Paris. p. 19.

(*) CILLI, V. - 1930 - Reazioni allergiche per la diagnosi precoce di sclerostomiasi negli equini mediante l'impiego di antigene specifico (strongilina). Nuova Veter. 15 (12), 365-9.

(') COCU \& HUE - 1896 - Contrib. à la pathol. d. anévrismes vermineux chez le cheval (Rap. de Railliet). Bul. Soc. Cent. Méd. Vét. 50, 394-407.

Cram - 1921 - A case of nanism in S. vulgaris \& obs. on the leaf crowns in species of Strongylus. J. of Parasitol. 7 (4), 188-9, Figs. 1-3.

De Blieck, L. \& Baudet, E. - 1926 - Contrib. a l'étude du dével. d. Strongylidés (Sclerostomes) du gros int. chez le cheval, Ann. Par. Hum. Comp. 4 (1), 87.96.

(1) Os trabalhos marcados com o signal (") não foram consultados no original. 
Foster, A. O. - 1936 - Parasitic worms of equine in Panama. Proc. Helminthol. Soc. Wash. 3, 59-60.

Foster, A. O. - 1936 - A Quantitative study of the Nematodes from a selected group of equines in Panama. The Jour. of Parasitol. 22, (5), 479-510.

Foster, A. O. - 1937 - A Relationship in equine between age of host and number of Strongylid parasites. The Amer. Jour. of Hyg. 25 (1), 66-75.

Foster, A. O. \& CLARK, H. C. -- 1937 - Verminous aneurysm in equines of Panama. Jour. of Trop. Med. 17 (1), 85-98, Pl. 1-3.

FRöHNER \& ZWICK - 1932 - Patol. y Ter. Vet. Barcelona. 1, 141-8, 223-231.

Glage, F. - 1906 - Beitr. z. Kenn. de Pallisadenwurmkrankheiten der Füllen und der Pferde. Zeit. $f$. Infek. d. Haust. 1 (4, 5), 341-375.

HALL, WILSON \& WIODOR - 1918 - The ant elminthic treatment of equine intestinal strongylidosis. J. Vet. Med. Ass. 6 (7), 47-55 Ref. in Rec. Méd. Vét. 1919: 70-1.

(*) Herino - 1830 - Mém. sur les anévrysmes internes du cheval. Rec. Méd. Vét. p. 433.

(*) Hodason - 1815 - Engravings intended to illustr. some of the diseases of arteries. London.

IHLE, J. E. W. - 1922 - Rep. of the Comm. app. to inquire into the Sclerostomiasis in Holland. I. Zool. Part. vol. 1. The adult Strongylids (Sclerostome) inhabiting the large intest. of the horse. 19-26, Figs. 1-9.

KITT, TH. - 1911 - Lehrbuch der Pathol. Anat. der Haustiere. Vierte Auflage. II. 386-392, Figs. 134-137.

LANE, C. - 1914 - Bursate Nematodes from the Indian elephant. The Ind. Jour. Med. Res. 2 (1), 380-398, Pl. 52, Figs. 15-24.

Leneven, G. - 1915 - Contrib, a l'étude d. affect. par. d. cheval. Étude clinique d. l. strongylidose équine. Rev. Géln. Méd. Vét. 24 (288), 593-612.

LEwIS, E. A. - 1926 - Helminths collected from Horses in the Aberystwyth Area. Jour. of Helminthol. 4, (4-5), 179-182

Looss, A. - 1900 - Notizen z. Helminthologie Egyptens. III. Die Sclerostomen der Pferde und Esel in Egypten. Centbl. f. Bak. 27 (4), 150. (5), 184.

Looss, A. - 1902 - The Sclerostomidae of horses and donkeys in Egypt. Rec. Egypt. Gov. School. of Med. 1901. pp. 2-139, Pl. 1-2, Fig. 1-19 (Trabalho classico).

Martin, O. - 1910 - Beiträge z. Kennt. d. Verbr. und Entw. d. Sclerostomum edentatum Looss. Arch. f. wiss, u. prakt. Tierheilk. 37 (1-2), 106-151. Fig. 1-6 \& $1 \mathrm{Pl}$.

MöNNIG, H. O. - 1924 - On Some new South African Parasitic Nematodes. Trans. Roy. Soc. South Africa. 11, 105-117, Figs 1-12.

Neumann, L. G. - 1892 - Traité des Maladies Parasitaires non Microbiennes des Animaux Domestiques. Paris. 601-609, Figs. 319-320.

(*) Olt - 1932 - Deut. Tier. Woch. 40 (21), 326-332.

Pinto, C. \& Almeida, J. Lins. de. - 1935 - Sinopse dos helmintos dos animais domesticos do Brasil. O Campo. 6 (8), 54-63, Figs. 1-10. Rio de Janeiro.

Pinto, C. \& Proença, C. -1936 - Etiologia dos aneurismas helminticos e strongylose equina. $O$ Campo. 7 (79), 53-56, Figs, 1-7. Rio de Janeiro.

(*) Poeppel, E. - 1897 - Unters. ueb. d. Bau von Strongylus armatus syn. Sclerostomum equinum Auctorum nebst einem Anhang ueber die Biologie desselben und das Aneurysma verminosum. Inaug. Diss. Leipzig. 8 pp. 157, Figs. 1-31.

Railliet, A. - 1895 - Traité de Zool. Méd. et. Agric. Paris. 455-460, Figs. 313-318.

RAILliet, A. - 1923 - Les Strongles (anciens Sclérostomes) et les strongyloses proprement dites. Rec. Méd. Vét. d'Alfort. 99 (13), 377-396.

Railliet \& Henry - 1902 - Sur les Sclérostomiens des Equides. C. R. Soc. Biol. Paris. 54, 110-2.

(*) Rigot - 1827 - De l'anévrysme spontané. Jour. Méd. Vét. \& Comp. p. 315.

(*) RuYsCH, Fr. - 1665 - Dilucidatio valvalarum. La Haye \& Opera omnia. 1737 (1), 16.

ANricchi, A. - 1907 -- Lesioni polmonari prodotte dagli Strongilidi. Arch. de Parasitologie. Paris. 11, 621-640, Figs. 1-19. 
(*) Schlegel, M. - 1907 - Die Sklerostomenseuche (Sklerostomiasis) d. Pferdes. Mitt. d. Vereins badischer Tierärzte. 7 (2), 23-31 \& Berl. tier. Woch. 4 (24 Jan), 49-55 \& 5 (31 Jan), 67-73.

(*) Schulze, J. H. - 1725 - Act. phys. med. nat. cur. 1, 519.

SChWARTZ, B. \& Cram, E. B. - 1925 - Horse parasites collected in the Philippine Islands. The Philip. Jour. Sci. 27 (4), 495-505, PI. 1-3.

(*) STICKer, A. - 1901 - Unters, ueber. Bau und die Lebensges. des Sclerostomum armatum. Arch. f. wiss. u. prakt. Tierheilk. 27 (3-4), 187-232, Taf. 2.

StICKeR, A. - 1901 - Der Aufenhart von Sclerostomum armatum in der Wand des Dickdarms. Ein Beitr. zur kolik des Pferdes. Deut. tier. Woch. 9 (25), 253-7.

(“) Sticker, A. - 1901 - Die drei Arten des bewaffneten Palissadenwurmes. Eine zool. und pathol. Studie. Deut. tier. Woch. 9 (33), 323-336, (34), 346-7.

Travassos, L. - 1917 - Principais helmintoses observadas no gado de córte no Brasil. 1.o Congresso Nacional de Pecuária.

Thwaite, J. W. - 1928 - A Contrib. to the study of the par, life hist. of Strongylus equinuts MUEL. - 1780 - together with a descript. of some lesions found in a donkey as a result of dosing with the infective larvae of this parasite. Ann. Trop. Med. \& Parasitol. 22, 291-302, Fig. 1. PI. 21.

THEILER, G. - 1923 - The Strongylids \& other Nematodes parasitic in the Intestinal tract of South African Equines. (Trav. du Lab. de Zool. Univ. de Neuchatel) pp. 30-33.

Vaz, Z. - 1930 - Nematóides de Equídeos observados no Brasil. Rev. Soc. Paul. Med. Vet. 1 (5), 3-6.

VAZ, Z. - 1934 - Trichonema (Cylicostephanus) parvibursatum n. sp. Nematóide parasito do intestino grosso de cavalo. Rev. Biol. \& Hyg. S. Paulo. 5 (2), 71-74.

Veiga, O. - 1916 - Strongylose dos cavalos. Trab. do Inst. Butantan. In Col. de trabalhos. Inst. Butantan. S. Paulo. 1918, 285-296.

YORKE \& MACFIE - 1918 - Strongylidae in Horses: I. Cylicostomum longibursatum sp. n. II. Cylicostomum minutum sp. n. III. Cylicostomum nassatum Looss. var. parvum. Ann. Trop. Med. \& Part. 11 (4), 399-416.

YORKE \& MACFIE - 1918 - Strongylidae in Horses. IV. Gyalocephalus capitatus Looss. V. Gyalocephalus equi sp. n. Ann. Trop. Med. \& Par. 12 (1), 79-92.

YORKE \& MACFIE - 1919 - Strongylidae in Horses. VI. Cylicostomum pseudocatinatum sp. n. Ann. Trop. Med. \& Par. $12(3,4), 273-278$.

YORKE \& MACFIE - 1919 - Strongylidae in Horses. VII. Cylicostomum pateratum sp. n. Ann. Trop. Med. \& Par. 13 (1), 57-62.

YORKE \& MACFIE - 1919 - Strongylidae in Horses. VIII. Species found in American Horses. Ann. Trop. Med. \& Par. 13 (2) 137-143, Pl. 4-6.

Yorke \& Southwell $-1920-$ Crossocephalus zebrae sp. n. Ann. Trop. Med. \& Par. 14 (1) $127-135$.

YORKE \& MACFIE - 1920 - Strongylidae in Horses. IX. Cylicostomum tridentatum sp. n. X. On the genus Poteriostomum Quiel. XI. Species found in West Africa and Jamaica. XII. Cylindropharynx rhodesiensis sp. n. XIII. Cylicostosmum triramosum sp. n. Ann. Trop. Med. \& Par. 14 (2), 153-179.

YORKE \& MAPLESTONE - 1926 - The Nematode Parasites of Vertebrates. London, J. \& A. Churchill: 34-38, Figs. 10-11. 


\section{EXPLICACAO DAS ESTAMPAS}

Est. 12 - Fotografia de ancurisma globuloso da artéria grande mesentérica do cavalo 240. As setas indicam as larvas de Strongylus vulgaris que determinam aquela lesão, Neste aneurisma foi encontrado tambem o Trichonema goldi. Segundo C. Pinto \& Cavalcanti Proença. 1936.

Est. 13 e 14-Fotografia de uma parte da curva diafragmatica do colon do cavalo 240 , com grande infestação por Strongylus edentatus, vulgaris e equinus (caso fatal). Segundo C. Pinto 8 Cavalcanti Proença. 1936.

Est. 15 - Fotografia mostrando, em tamanho natural as tres espécies de Strongylus: edentatus, vulgaris e equinus colhidas no colon do cavalo 240. Segundo C. Pinto \& Cavalcanti Proença. 1936.

Est. 16 - Fotografia da aorta abdominal $(A)$ de cavalo, vendo-se à esquerda a artéria grande mesentérica (M) com um aneurisma produzido por larvas de Strongylus vulgaris. J. Pinto fot. Original.

Est. 17 - Aneurisma fusiforme da artéria grande mesentérica do cavalo, produzido por larvas de Stron. gylus vulgaris J. Pinto, fot. Original.

Est. 18 - $O$ mesmo aneurisma da fotografia 17, aberto no sentido longitudinal. J. Pinto, fot. Original.

Est. 19 - Corte histológico da artéria grande mesentérica do cavalo (240) com aneurisma produzido por larvas de Strongylus vulgaris, vendo-se lesões pronunciadas nas tres túnicas. Na túnica interna as setas indicam os cortes dos helmintos contidos em trombos; alguns destes trombos são recentes e outros em formasão. Na túnica média existe acentuada fibrose e presença de cicatrizes, alem de lesões dos vasa vasorum. A túnica adventicia é consideravelmente espessada em consequência da neo formação de tecido conjunctivo. $X 4$. J. Pinto, fot. Original.

Est. 20-Corte histológico da túnica interna da artéria grande mesentérica do cavalo (240) com aneurísma helmintico por larvas de Strongylus vulgaris. Vê-se um exemplar do helminto contido num trombo, $\times 20$. J. Pinto, fot. Original.

Est. 21 - Corte histológico da túnica interna da artéria grande mesentérica do cavalo (240) com aneurísma helmintico por larvas de Strongylus vulgaris; vêm-se dois exemplares do helminto (cortados transversalmente), contidos num trombo. $X 45$. J. Pinto, fot. Original

Est. 22 - Corte transversal de um exemplar da larva de Sirongylus vulgaris do aneurisma helmintico da artéria grande mesentérica do cavalo (240). X 105. J. Pinto, fot. Original,

Est. 22-A - Corte histológico de um abcesso do intestino de cavalo, contendo um exemplar da larva do ultimo estádio de Strongylus vulgaris proveniente do Rio de Janeiro. O helminto foi retirado na ocasião de abrir-se 0 abcesso. $\times 7 . \mathrm{J}$. Pinto, fot. Original.

Est. 23-Habronemose gástrica por Draschia megastoma, constituida por um nódulo inflamatório com intensa necrose de sua parte central, transformada assim em cavidade. Em seu interior, vê. se massa caseosa cinzenta indicada pelas setas contendo o helminto productor da lesão. O nódulo inflamatório se localisa no saco direito do estômago do cavalo. $\times 2$. J. Pinto, for. Original.

Est. 24-Porção do saco direito do estômago de cavalo, contendo um nódulo inflamatório, com 2,5 cents. de diametro, produzido por Draschia megastoma. Vê-se a abertura do trajecto fistuloso (indicado pela seta) que comunica a cavidade do estômago com a cavidade do nódulo habronémico.

Os nódulos habronêmicos se localisam, de preferência, no limite da mucosa gástrica (m. g.) com a mucosa cardiaca (m, c.). $\times 2$, Na Est. 25 về-se este nódulo aberto. J. Pinto, fot. Original.

Est. 25 - Fotografia de um nódulo inflamatório nas paredes do saco direito do estômago de cavalo. A sua porção central necrosada é transformada em cavidade, encerra numerosos exemplares de Draschia megastoma (indicados pelas setas) productor da lesão. A cavidade comunica-se, por meio de um trajecto fistuloso, com a cavidade do estomago. $X 2$. J. Pinto, fot. Original.

Est. 26 - Córte longitudinal da extremidade cefálica de Strongylus edentatus preso á parede do intestino de cavalo proveniente do Rio de Janeiro. A porção do tecido contida na boca do hel. minto, tem estrutura semelhante á da submucosa; em sua porçăo basal estreitada e pediculada existe necrose das células aí presentes.

$O$ pequeno fragmento das paredes do intestino contido na boca do helminto não é mais recoberto pela mucosa.

$\mathrm{Na}$ submucosa existe apenas infiltração discreta por leucocitos eosimofilos na visinkança dos vasos. J. Pinto, fot. $X 46$. Original.

Est. 27 - Córte Iongitudinal da extremidade anterior de Strongylus edentatus no intestino de cavalo do Rio de Janeiro. $\times 25$, J. Pinto, fot. Original.

Est. 28 - Fotografia de dois fragmentos do figa do de Equus caballus do Rio de Janeiro, vendo-se quatro larvas de Strongylus equinus localisadas sob a cápsula de Glisson. Fot. em tamanho natural. J. Pinto, fot. Original. 
C. Pinto e C. Proença, Etiol, dos aneurismas helmínticos Rev. Fac. Med, Vet. S. Paulo, Vol.1, fasc. 1 Estampas 12 e 13



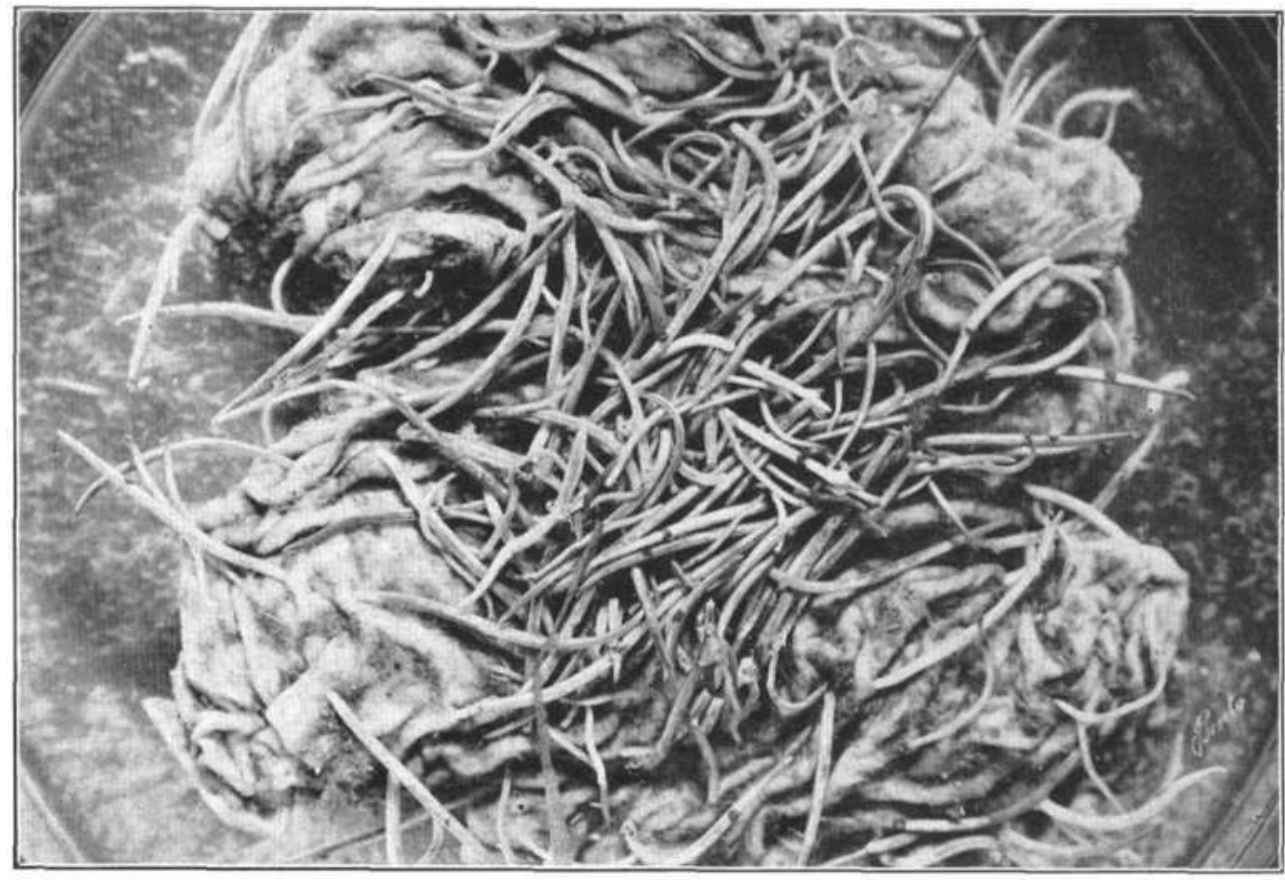

14















19

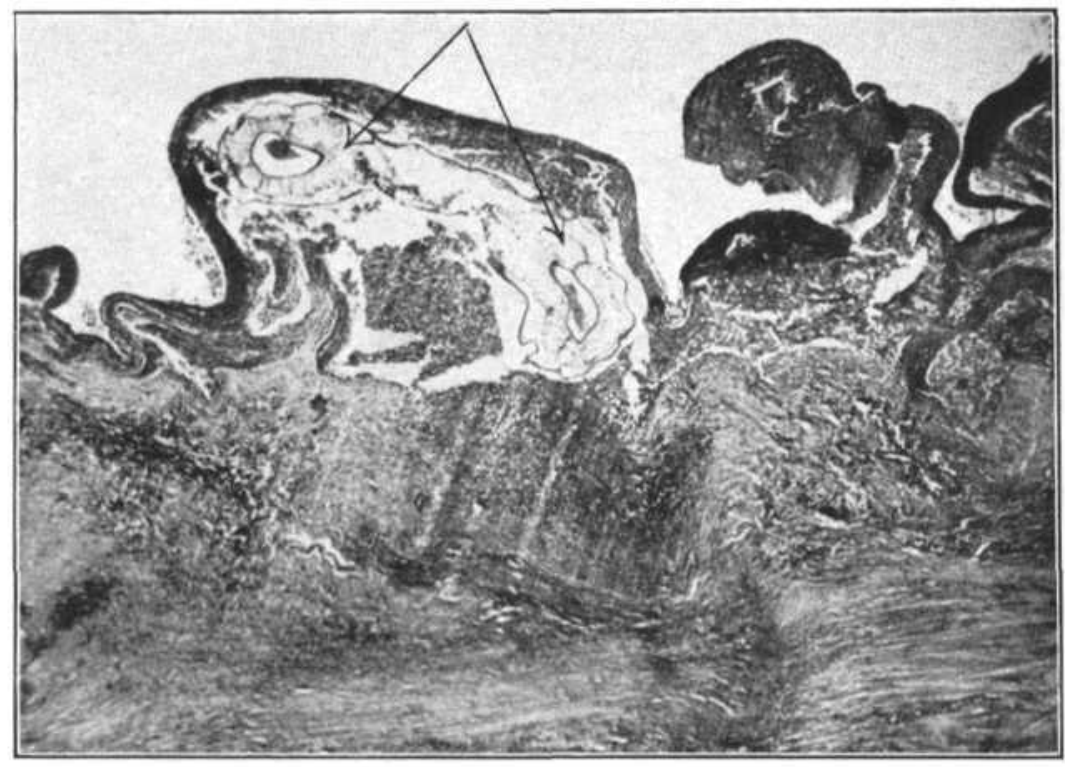



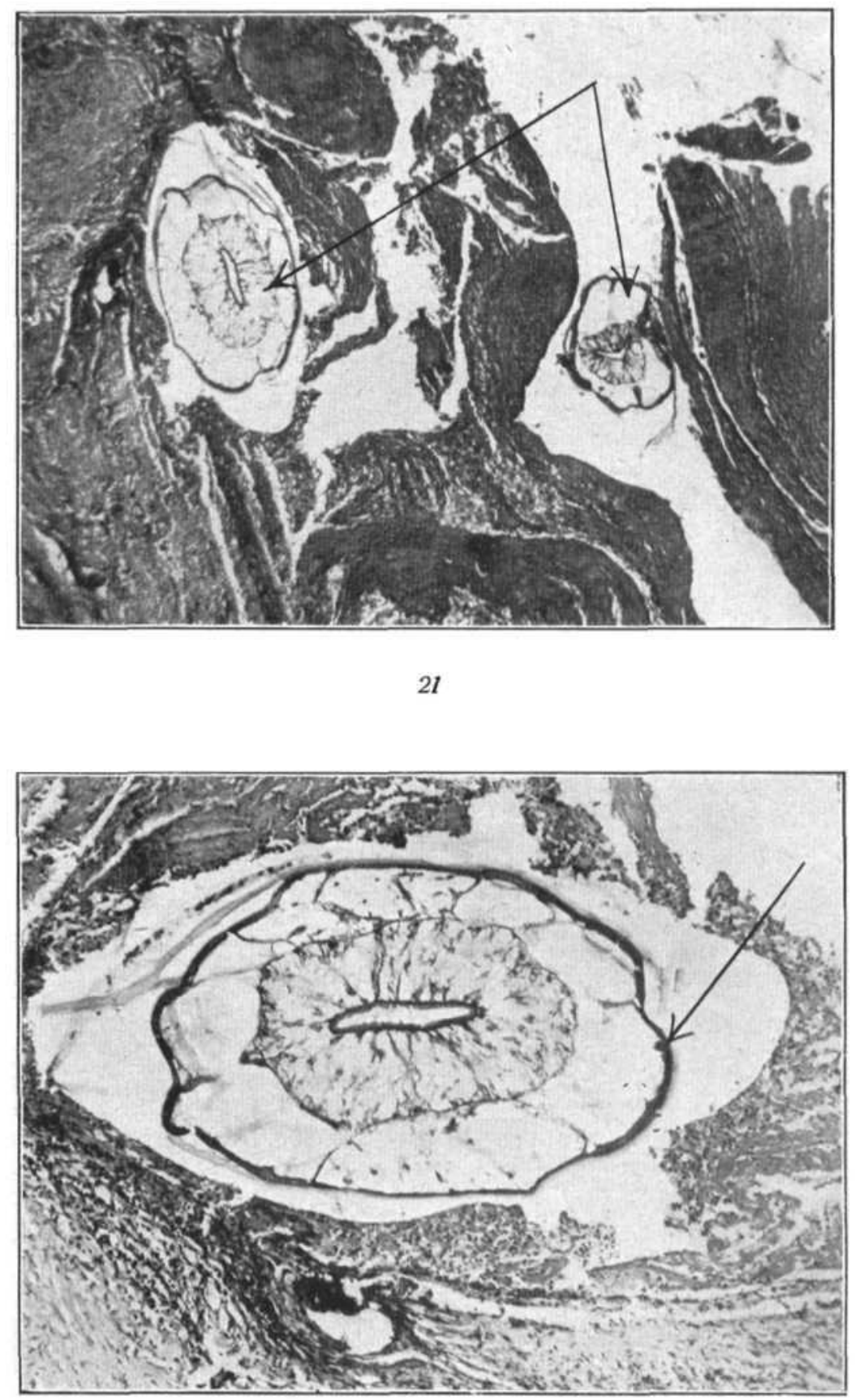




23

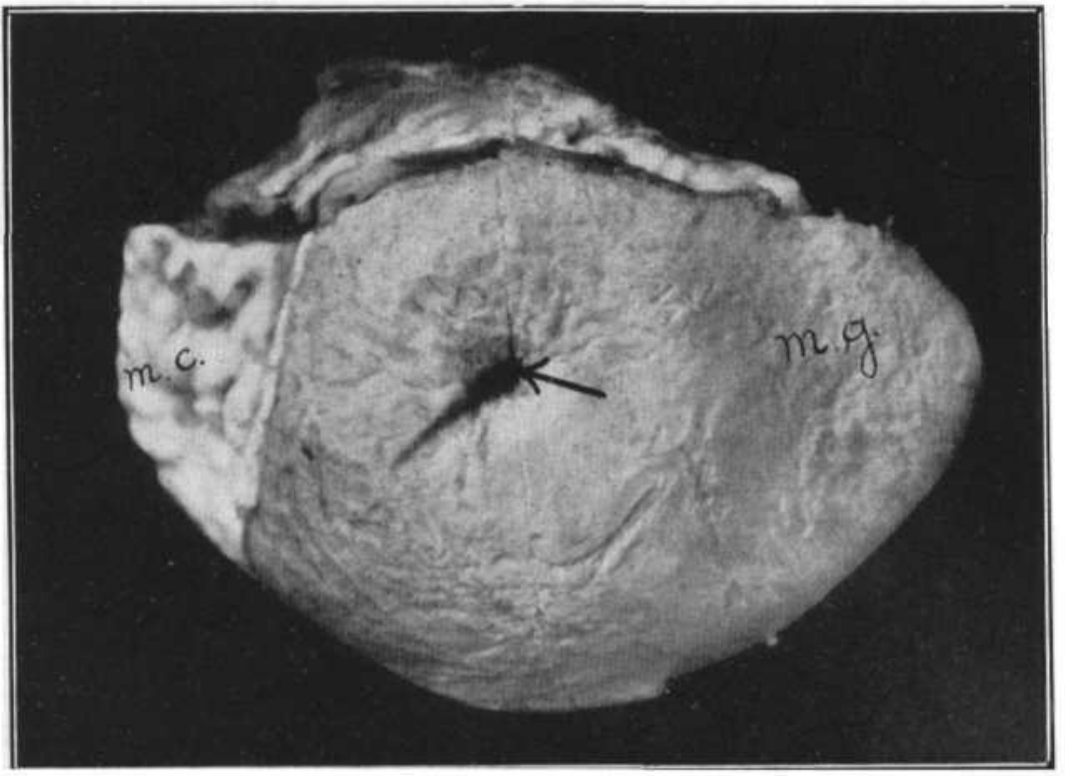





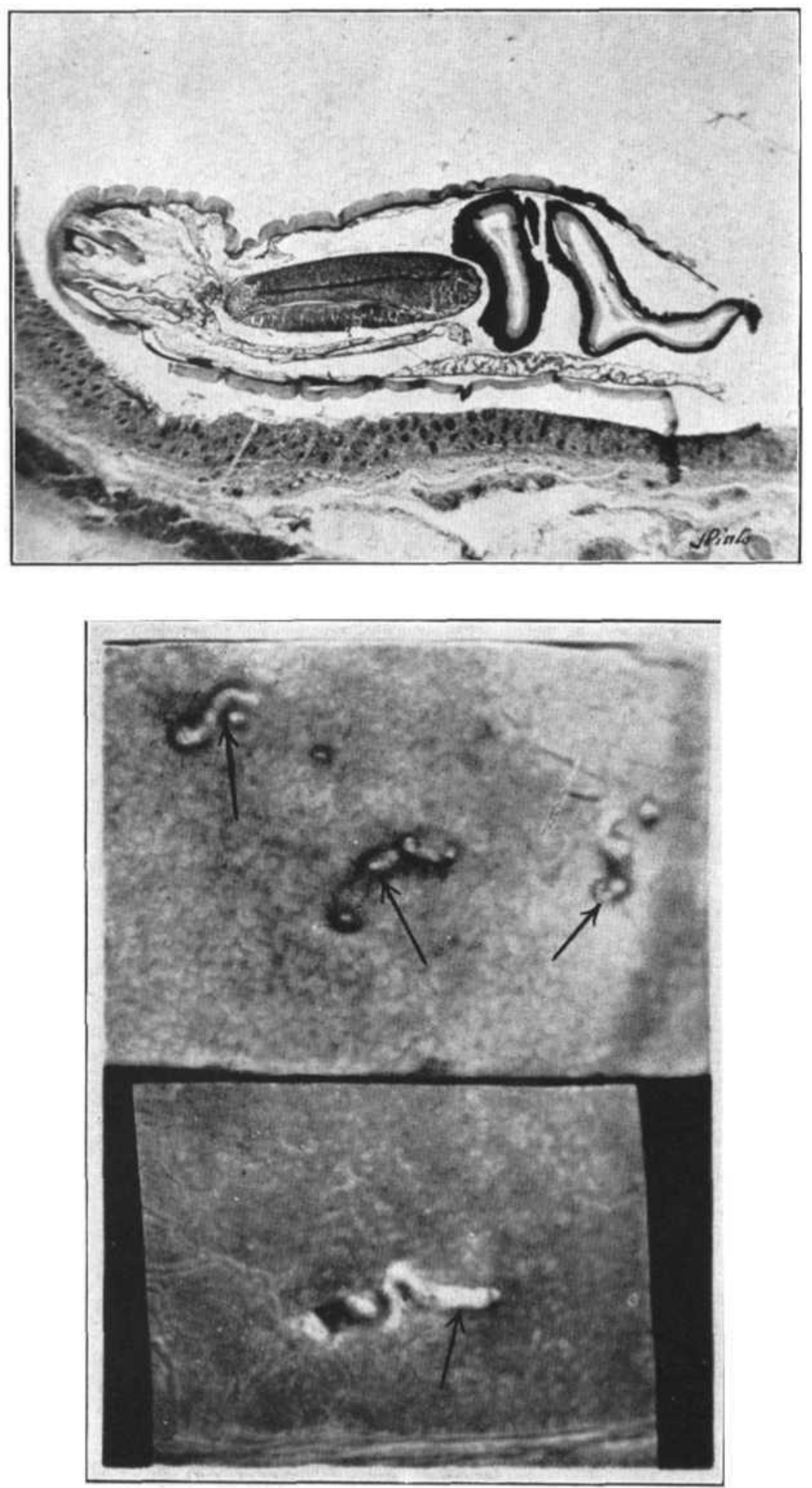